\title{
Productivity and Internationalization: A Micro-Data Approach
}

\author{
Peter A. G. van Bergeijk • Fabienne Fortanier • \\ Harry Garretsen - Henri L. F. de Groot • \\ Selwyn J. V. Moons
}

(C) The Author(s) 2011. This article is published with open access at Springerlink.com

\begin{abstract}
An appropriate analysis of the effects of globalization requires a careful analysis of the various ways in which different firms operate in international markets. Micro data at the level of individual firms and employees can enhance our empirical understanding of the relationships between internationalization, firms, jobs and employees. These micro data become increasingly available. This paper provides an introduction to this special issue that illustrates the wide variation, richness and policy relevance of the emerging micro data driven research on the effects of internationalization and productivity.
\end{abstract}

Keywords Globalization · International trade · Productivity · Micro data · Firm heterogeneity

\footnotetext{
The authors are the joint organizers of a conference with the same title as this special issue held in September 2010 in The Hague. The program of the conference is available at http://www.microdata2010.nl. All papers in this issue were presented at the conference.
}

\author{
P. A. G. van Bergeijk \\ International Institute of Social Studies of Erasmus University, The Hague, The Netherlands \\ F. Fortanier \\ CBS Statistics Netherlands, The Hague, The Netherlands \\ H. Garretsen \\ University of Groningen, Groningen, The Netherlands \\ H. L. F. de Groot ( $\varangle)$ \\ Department of Spatial Economics, VU University Amsterdam, Amsterdam, The Netherlands \\ e-mail: h.l.f.de.groot@vu.nl
}

\section{S. J. V. Moons}

Ministry of Economic Affairs, Agriculture and Innovation, The Hague, The Netherlands 
JEL Classification $\mathrm{D} 20 \cdot \mathrm{F} 10 \cdot \mathrm{F} 14 \cdot \mathrm{F} 21 \cdot \mathrm{L} 10 \cdot \mathrm{O} 12$

\section{Globalization and Productivity}

The economic debate about the costs and benefits of globalization was-for a long time - based on traditional macroeconomic analyses and reasoning. This literature is theoretically as well as empirically well developed showing a substantial and positive impact of trade and trade openness on GDP (see, for example, Frankel and Romer 1999; Sachs and Warner 1995; Lewer and van denBerg 2003). The perspective on the impact of globalization - especially regarding the fundamental causal question whether trade increases productivity or more productive firms just trade more-changed importantly by the applications and extensions of the New Trade Theory developed in the early 1980s following the seminal work by scholars like Paul Krugman and Elhanan Helpman (see, for example, Helpman and Krugman 1985), and the seminal work by Mark Melitz (2003) that focuses explicitly on the microeconomic underpinnings and therefore was able to point out the relevance of heterogeneity across firms. The empirical counterpart of this research has greatly benefited from the increased availability of individual and firm level data, allowing researchers to identify the importance of heterogeneity. Also in the Netherlands micro data research has recently made a head start as testified by the articles in this special issue (see also Kox and Rojas-Romagosa 2010, and Creusen and Lejour 2011, for recent examples).

It has become increasingly clear that an appropriate analysis of the effects of globalization requires a careful rethinking of the various ways in which different firms operate in international markets. Globalization affects the economy not only across traditional sectoral lines, but may also have strong effects within particular industries, with winners and losers in each industry. One of the most well-known and robust results is that more productive firms tend to engage more in trade, FDI and slicing up of value chains than their less productive competitors hinting at the relevance of set-up costs of internationalization. The impact of globalization may thus have very different effects on individual firms, tasks, occupations and regions (see Bernard et al. 2007, for a review of this line of research, and also Syverson 2011, for a discussion of the impact of trade competition on productivity).

Some have concluded that, since production tasks and services are increasingly outsourced, the era of globalization has entered a new stage, where trade in tasks is more important than trade in goods. These findings suggest that globalization dynamics may have effects that go beyond potential negative consequences for low-skilled workers. For example, several authors found that, especially during the 1990s, the labor market effects of globalization follow an inverted U-curve in the sense that medium skilled workers have been hit harder than those with higher and those with lower skills (see, for example, Autor et al. 2006). Antras et al. (2006) and Garicano and Rossi-Hansberg (2006) provide a theoretical framework that shows that globalization, and in particular off-shoring, could have wide ranging effects on the reallocation of tasks. These developments are likely to be further enhanced by current trends in ICT applications, accompanied by increasing tradability of services (Baldwin 2006 and Blinder 2005, 2006). As a result, it is increasingly likely that globalization is of major importance 
for developments within industries and for the position of workers with specific tasks at various skill levels. Altogether this implies a decreasing relevance of labor market analysis along traditional sectoral classifications, in favor of a microeconomic approach that accounts for firm and worker heterogeneity.

\section{Also Policy Makers Should Care}

The continuing trend toward globalization raises several questions that are highly relevant, in particular for a small open economy like the Netherlands. Economists typically tend to emphasize the finding that trade liberalization is beneficial to aggregate social welfare. This is confirmed by empirical evidence that shows that 'the range of possible effects is bounded below by zero' (cf. Alesina et al. 2005). How these benefits are distributed (and redistributed) is, however, empirically less clear cut and is the subject of intensive political debate and an important topic in the field of political economy. It is only recently that increasing attention has been paid to carefully distinguishing the potential positive as well as negative effects that globalization may have.

An early wave in the literature mainly pointed at the potential negative effects of globalization on labor intensive (skill extensive) industries, with low educated workers facing increased competition from low wage countries. Consequently, globalization may be a source of increased wage inequality, and a cause of job loss at the bottom of the labor market (Berman et al. 1998). Especially increasing wage inequality in the United States is regularly attributed to globalization, although skill biased technological progress, changing labor market institutions and minimum wages are often seen as important alternative explanations (IMF 2007; Lawrence 2008).

A second line of analysis in the firm heterogeneity literature clarifies that a onesize-fits-all policy approach will be unproductive. Van den Berg et al. (2008) provide a social cost-benefit analysis of Dutch trade policy instruments that illustrates that criteria based on economic performance and a realistic assessment of potential success should be applied to select firms that can participate in costly export promotion activities such as state visits.

Thirdly, authors have suggested that more attention should be paid to the micromacro paradox inherent in the new literature (van Bergeijk 2009), in particular regarding the question where the macroeconomic welfare gains derive from if firms do not become more productive when they internationalize their commercial activities. This paradox can be reconciled when we consider industry restructuring (successful firms driving out less productive firms) and dynamic competition effects (international competition making firms more productive). This adjustment process to globalization and its impact on Total Factor Productivity (TFP) plays an important role in recent theoretical models (Melitz 2003; Bernard et al. 2008).

A better understanding of the relationships between internationalization, firms, jobs and employees thus requires an empirical approach that makes use of data at the level of individual firms and employees. These micro data become increasingly available, also in the Netherlands through CBS Statistics Netherlands (see, for example, CBS 2010; Fortanier et al. 2011). This issue takes stock of recent developments in this flourishing field of research, with a special focus on how to actually measure the consequences 
of globalization for value added and productivity. How does the increasing global interconnectedness of nations, firms and consumers impact factor productivity and economic growth? Given these questions, an adequate grasp of the opportunities and limits of quantitative analysis using micro data is vital for statisticians, academics and policy makers.

\section{Setup of this Issue}

This issue contains five contributions illustrating the wide variation, richness and policy relevance of the emerging micro data driven research on the effects of internationalization and productivity. The first contribution by Joachim Wagner surveys some of the key challenges in this branch of research. Based on his long experience and as one of the leading scholars in the area of the new new trade theory, he comes up with twelve important recommendations that clearly have relevance far beyond this specific field of research. The paper thereby neatly sets the stage for doing micro data analysis in general and for this special issue in particular.

The issue then proceeds with four empirical contributions that are all based on Dutch micro data. The second paper by Creusen et al. is an outgrowth of a project by the CPB Netherlands Bureau for Economic Policy Analysis on globalization and surveys several of the key insights that have been obtained for the Netherlands focusing on the margins of Dutch exports. The findings for the Netherlands are in line with international consensus emphasizing the importance of selection effects. Only the more productive firms are found to engage in exports. These are the more productive firms that can incur the costs associated with institutional and cultural barriers to trade. Also, the paper addresses the importance of the "learning to export" phenomenon and it concludes with a discussion of policy implications.

In the third paper of this issue a novel approach is developed by Akçomak et al. This paper is a fine example of the possibilities new micro data have to offer. It focuses on the functional classification of jobs and emphasizes that the division of labor occurs at three distinct levels, viz. the level of the individual worker, the level of the industry and the spatial level. The paper illustrates that the unbundling of tasks is to a large extent driven by progress in the information and communication technologies in the period 1996-2005. This insight can to a large extent explain the changes in the structure of unemployment.

The potential policy implications of micro data driven research are illustrated in the fourth paper by Vancauteren and De Frahan. They quantify the impact of harmonization of regulations in the European Union on total factor productivity of firms. The micro data allow the researchers to investigate the channels through which harmonization affects productivity. The authors conclude that enhanced competition-resulting in lower markups-is a key driver of faster productivity growth.

The fifth and final paper by Fortanier and Moons focuses on the heterogeneity of inward Foreign Direct Investments in the Netherlands. The relevance of inward FDI is a highly relevant issue in policy circles. How much efforts should be devoted to attract foreign firms to the Netherlands? How do the foreign investments differ in their effects? To what extent may spillover effects be expected to firms in the direct vicinity 
of these newcomers? This field of research is notoriously difficult in view of the lack of reliable data. Thus, the paper makes a valuable contribution by illustrating for the Netherlands the extent to which foreign firms are different in terms of employment and productivity and how these differences may be related to differences in function, sector and country of origin.

\section{Challenges Ahead}

As becomes clear from contributions in this issue, the empirical research exploiting micro data is still in an early phase. Important progress is to be expected in the coming decades. We conclude this introduction with a sketch of key challenges that are ahead.

Micro data research on the effects of globalization is gradually developing attracting an increasing number of researchers. Any researcher using micro data is aware of the tremendous efforts that are required in this field of research. Data are often difficult to find and access. Commercial source are often expensive and of uncertain quality. Data from statistical offices are oftentimes primarily collected for the purpose of generating aggregate data to construct national accounts, using stratified samples that vary over time in an attempt to minimize the response burden on firms, making longitudinal micro data integration difficult. In both cases, the process of preparing the data for analysis is highly time-consuming. Stronger national and international cooperation between statistical offices and research organizations is therefore essential. It will also create huge value added in bringing this type of research steps ahead. It requires continued mutual investments in creating understanding of the different parties' working methods, interests and (institutional) constraints in order to create trust on both sides. In periods where many statistical offices are facing drastic financial cutbacks, such cooperation is vital for ensuring continued and innovative relevant statistical information, not only at the aggregated but also at the micro level. The potential returns from cooperation are huge in view of the complexity of the tasks that we are facing and the complementary knowledge that statisticians and researchers have to offer [see also Syverson (2011)].

A second challenge is related to the translation of research insights to the level of practical policy making. Messages from this line of research are almost unavoidable complicated. The 'it depends' type of answer for which economists are already notorious is an answer that is intrinsically embedded in this branch of research that studies variation in firm behavior. Research on firm heterogeneity is most likely to further highlight that the effectiveness of economic policies is almost always conditional. Selection of firms to which policies should be targeted is, however, notoriously complex and requires smart policy designs that make optimal use of self-selection mechanisms. Enhancing our understanding of the relevant conditionalities is in any case a critical first step. Subsequently moving ahead to concrete policy advice is complicated and will require the joint and coordinated development of theoretical and empirical research.

A third challenge is to move beyond individual country studies. Most empirical applications are confined to single countries. An important reason is that high quality and large sample micro data is only available at national statistical offices, which are legally prohibited to exchange data across national borders (and sometimes 
even within the same statistical office) due to privacy and confidentiality concerns. There are several ways forward. One is to link existing micro data, but in view of the several restrictions that are imposed on the use of these data, this solution is likely to require substantial investment, both financially and time wise. An alternative is to perform perfectly comparable analyses on data from different countries and to compare and integrate the outcomes. Meta-analysis provides us with useful tools to do this in a statistically sound way (see Florax et al. 2002, and also one of the recommendations by Joachim Wagner in this special issue). The relevance of this line of research is that it allows us to draw conclusions that require variation across countries, for example regarding the impact of different institutional settings on economic outcomes. Finally, strong international cooperation —ideally to be coordinated by Eurostat—could generate national micro datasets that are comparable across countries. Through joint analysis protocols, these can be used to shed light on common aspects and differences between firms that operate in different national contexts. A recent example of such a project involves the survey and subsequent micro data linking exercise on international sourcing, that was carried out by the Statistics offices of Denmark, Finland, the Netherlands, Norway and Sweden (Statistics Denmark 2008).

Fourth, the use of increasingly detailed and rich micro data for international economics research involves important measurement challenges (see Fortanier and van de ven 2009). At the micro level, researchers are confronted with the fact that many activities associated with more complex forms of internationalization (like sending goods abroad for processing, transit trade and re-exports) affect the data quality of many of the key variables of concern such as production, value added, input and output. It is exactly because of the discrepancies in the data quality between firms that do and do not operate internationally, that comparisons between the two types of firms become increasingly difficult. The contribution of globalization to national economies therefore becomes more difficult to assess. An adequate grasp of the opportunities and limits of micro data is hence vital to avoid drawing wrong conclusions. This further adds to the need to integrate more strongly the work of statistical offices on the one hand, and academic researchers and policy makers on the other hand, in measuring and analysing the consequences of internationalization.

Empirical research building on micro data is hence a daunting but rewarding type of research. It provides us with the possibility to empirically assess the relevance of recent theoretical contributions that emphasize the importance of heterogeneity. The contributions in this issue illustrate the usefulness of this type of research, with a focus on the Netherlands. In view of the recent nature of this research, important new contributions are still to be expected that can further enhance our understanding of the complex impact of globalization and the possibilities to develop sound policies that can target the right groups in an attempt to further reap the benefits that increased integration can provide.

Acknowledgments Financial support of the Ministry of Economic Affairs is gratefully acknowledged. Also support from CPB Netherlands Bureau for Economic Policy Analysis, CBS Statistics Netherlands, NICIS Institute and Janneke van der Meulen has been valuable in turning this initiative into a success. The views in this paper in no way reflect those of the institutes to which the authors are affiliated. 
Open Access This article is distributed under the terms of the Creative Commons Attribution Noncommercial License which permits any noncommercial use, distribution, and reproduction in any medium, provided the original author(s) and source are credited.

\section{References}

Alesina, A., Spolaore, E., \& Wacziarg, R. (2005). Trade, growth and the size of countries. In P. Aghion \& S. Durlauf (Eds.), Handbook of economic growth (pp. 1499-1542). New York: Elsevier.

Antras, P., Garicano, L., \& Rossi-Hansberg, E. (2006). Offshoring in a knowledge economy. Quarterly Journal of Economics, 121(1), 31-77.

Autor, D. H., Katz, L. F., \& Kearney, M. S. (2006). The polarization of the US labor market. American Economic Review, 96(2), 189-194.

Baldwin, R. (2006). Globalisation: The great unbundling(s). Downloadable at http://www.vnk.fi/hankkeet/ talousneuvosto/tyo-kokoukset/globalisaatioselvitys-9-2006/artikkelit/Baldwin_06-09-20.pdf.

Berman, E., Bound, J., \& Machin, S. (1998). Implications of skill-biased technological change: International evidence. Quarterly Journal of Economics, 113(4), 1245-1279.

Bernard, A. B., Redding, S. J., \& Schott, P. K. (2008). Comparative advantage and heterogeneous firms. Review of Economic Studies, 74(1), 31-66.

Bernard, A. B., Jensen, J. B., Redding, S. J., \& Schott, P. K. (2007). Firms in international trade. Journal of Economic Perspectives, 21(3), 105-130.

Blinder, A. S. (2005). Fear of offshoring, CEPS Working Paper, no. 119, Princeton University, Princeton.

Blinder, A. S. (2006). Offshoring: The next industrial revolution?. Foreign Affairs, 85(2), 113-128.

CBS. (2010). Internationalisation monitor 2010. The Hague/Heerlen: CBS Statistics Netherlands.

Creusen, H., \& Lejour, A. (2011). Uncertainty and the export decisions of Dutch firms, CPB Discussion Paper, no. 183, CPB Netherlands Bureau for Economic Policy Analysis, The Hague.

Florax R. J. G. M., de Groot, H. L. F., \& de Mooij, R. A. (2002). Meta-analysis: A tool for upgrading inputs of macroeconomic policy models, Tinbergen Discussion Paper, no. 2002-041/3, Amsterdam-Rotterdam.

Fortanier, F., Korvorst, M., \& Luppes, M. (2011). The employment consequences of globalization: Linking data on employers and employees in the Netherlands. In A. Di Ciaccio, M. Coli, \& J. Angulo Ibanez, Advanced statistical methods for the analysis of large data-sets. New York: Springer.

Fortanier, F., \& van de ven, P. (2009). Globalization and national accounts: Consequences of inward foreign direct investment for productivity at the micro and meso level, invited Paper presented at ISI conference. Durban, South Africa (17-22 August).

Frankel, J. A., \& Romer, D. (1999). Does trade cause growth. American Economic Review, 89(3), 379-399.

Garicano, L., \& Rossi-Hansberg, E. (2006). Organization and inequality in a knowledge economy. Quarterly Journal of Economics, 121(4), 1383-1435.

Helpman, E., \& Krugman, P. R. (1985). Market structure and foreign trade: Increasing returns, imperfect competition and the international economy. Cambridge, MA: MIT Press.

IMF. (2007). World economic outlook. Washington: IMF.

Kox, H. L. M., \& Rojas-Romagosa, H. (2010). Exports and productivity selection effects for Dutch firms. De Economist, 158, 295-322.

Lawrence, R. Z. (2008). Blue-collar blues: Is trade to blame for rising US income inequality? Policy analysis in international economics, no 85, Peterson Institute for International Economics, Washington, DC.

Lewer, J. J., \& van den Berg, H. (2003). How large is international trade's effect on economic growth. Journal of Economic Surveys, 17(3), 363-396.

Melitz, M. J. (2003). The impact of trade on intra-industry reallocations and aggregate industry productivity. Econometrica, 71(6), 1695-1725.

Sachs, J. D., \& Warner, A. (1995). Economic reform and the process of global integration. Brookings Papers on Economic Activity, 1, 1-118.

Statistics Denmark. (2008). International sourcing: moving business functions abroad. Finland, Netherlands, Norway and Sweden: Statistics Denmark.

Syverson, C. (2011). What determines productivity?. Journal of Economic Literature, 49(2), 326-365. 
van Bergeijk, P. A. G. (2009). Economic diplomacy and the geography of international trade. Cheltenham: Edward Elgar.

Van den Berg, M., de Nooij, M., Garretsen, H., \& de Groot, H. L. F. (2008). MKBA Buitenlandinstrumentarium, SEO Report 2008-64, SEO, Amsterdam. 